EGU2020-21466

https://doi.org/10.5194/egusphere-egu2020-21466

EGU General Assembly 2020

(c) Author(s) 2020. This work is distributed under

the Creative Commons Attribution 4.0 License.

\title{
Extrapolating a spatially explicit tree root reinforcement model with field and LiDAR-derived stand data
}

\author{
Edoardo Alterio ${ }^{1}$, Andrea Rizzi ${ }^{1}$, Paolo Fogliata ${ }^{2}$, Niccolò Marchi ${ }^{1}$, Alessio Cislaghi ${ }^{2}$, Emanuele \\ Lingua ${ }^{1}$, Tommaso Sitzia ${ }^{1}$, and Gian Battista Bischetti ${ }^{2}$ \\ ${ }^{1}$ Department of Land, Environment, Agriculture and Forestry, Università degli Studi di Padova, Legnaro, Italy \\ ${ }^{2}$ Department of Agricultural and Environmental Sciences, Università degli Studi di Milano, Milano, Italy
}

Protection from landslides is one of the most important regulating services provided by forest ecosystems. Tree roots provide an increase in tensile strength, compression and shear resistance, compared to that uniquely due to the soil properties. This additional effect is known as root reinforcement. The degree of soil reinforcement given by roots have been modeled using laboratory and field data. The great spatial and temporal variability of root distribution is one of the main sources of uncertainty for the development of accurate and reliable models to quantify root reinforcement. The relative importance of stand structure remains poorly known. Here, we analyze the relationships between observed stand structure from a sample of spruce, beech, chestnut and mixed stands of the Southeastern Alps, and a spatially explicit model of root reinforcement. Data were collected in $20-\mathrm{m}$ radius sampling units inclined $15-40^{\circ}$ and covered by a low-resolution airborne LiDAR-derived canopy height model. Tree size and position were used to calculate root reinforcement through commonly used and calibrated models. Then, we studied the relationships between root reinforcement, stand structural indexes and area-based stand metrics from canopy height model. In specific conditions, the three groups of variables were correlated. Therefore, root reinforcement values might be spatially extrapolated through available canopy height models. Final step is to integrate the extrapolated values into a landslide susceptibility model, which combines other data available from forest plans, digital elevation models, geological and meteorological data. This study provides managers with a tool to periodically update maps of the service given by forest trees to protection of humans from landslides.

How to cite: Alterio, E., Rizzi, A., Fogliata, P., Marchi, N., Cislaghi, A., Lingua, E., Sitzia, T., and Bischetti, G. B.: Extrapolating a spatially explicit tree root reinforcement model with field and LiDAR-derived stand data, EGU General Assembly 2020, Online, 4-8 May 2020, EGU2020-21466, https://doi.org/10.5194/egusphere-egu2020-21466, 2020 